\title{
Cost effectiveness of the Oregon quitline "free patch initiative"
}

\author{
Jeffrey L Fellows, Terry Bush, Tim McAfee, John Dickerson
}

Tobacco Control 2007;16(Suppl I):i47-i52. doi: 10.1136/tc.2007.019943

See end of article for authors' affiliations

.....................

\section{Correspondence to:} Jeffrey L Fellows, PhD,

Center for Health Research, Kaiser Permanente

Northwest, $3800 \mathrm{~N}$

Interstate Ave, Portland, OR 97227, USA; jeffrey.

fellows@kpchr.org

Received 2 January 2007

Accepted 15 August 2007

\begin{abstract}
Objective: We estimated the cost effectiveness of the Oregon tobacco quitline's "free patch initiative" compared to the pre-initiative programme.

Methods: Using quitline utilisation and cost data from the state, intervention providers and patients, we estimated annual programme use and costs for media promotions and intervention services. We also estimated annual quitline registration calls and the number of quitters and life years saved for the pre-initiative and free patch initiative programmes. Service utilisation and 30-day abstinence at six months were obtained from 959 quitline callers. We compared the cost effectiveness of the free patch initiative (media and intervention costs) to the pre-initiative service offered to insured and uninsured callers. We conducted sensitivity analyses on key programme costs and outcomes by estimating a best case and worst case scenario for each intervention strategy.

Results: Compared to the pre-intervention programme, the free patch initiative doubled registered calls, increased quitting fourfold and reduced total costs per quit by $\$ 2688$. We estimated annual paid media costs were $\$ 215$ per registered tobacco user for the pre-initiative programme and less than $\$ 4$ per caller during the free patch initiative. Compared to the pre-initiative programme, incremental quitline promotion and intervention costs for the free patch initiative were \$86 (range \$22-\$353) per life year saved.

Conclusions: Compared to the pre-initiative programme, the free patch initiative was a highly cost effective strategy for increasing quitting in the population.
\end{abstract}

C igarette smoking is the number one cause of preventable death and disease in the United States. ${ }^{1}$ Telephone tobacco cessation quitlines have been an effective and convenient method for reducing smoking, and telephone counselling with medications can double quit rates..$^{2-5}$ Telephone quitlines are now available to smokers in every state. However, even though nearly half of all smokers make a quit attempt each year, only $1-5 \%$ call a state quitline. ${ }^{6}$ More can be done, but media campaigns to promote quitlines are expensive. ${ }^{67}$ In 2007, 21 states provided free nicotine replacement therapy (NRT) to at least some populations and 11 of these provided free NRT to all users. ${ }^{8}$ Providing free NRT increased the reach and effectiveness of the quitline services and promotion campaigns..$^{9-12}$

The Oregon Tobacco Prevention and Education Programme (TPEP) operates the Oregon tobacco cessation quitline as part of the state's comprehensive tobacco control strategy. Through a contract with Free \& Clear, Inc (F\&C) of Seattle, WA, counsellors provide a single brief telephone counselling session to registered tobacco users. Counsellors trained in cessation support techniques ${ }^{7}$ and motivational interviewing discuss quit plans and motivation, setting a quit date, relapse prevention and community resources for quitting; they also offer printed self help materials. Each year, TPEP enrols about $1 \%$ of Oregon's adult smokers. Funding, however, is limited and tenuous. TPEP only spends about one-sixth the Centers for Disease Control and Prevention's (CDC) recommended \$6.51 $(£ 3.2 ; € 4.8)$ minimum per capita. ${ }^{13}{ }^{14}$ From April to November 2003, budget cuts forced the quitline to suspend operations. The quitline was restored in December 2003, but services were limited to a single in-depth call and mailed quit kit.

In October 2004, TPEP initiated a strategy to increase the utilisation and effectiveness of the Oregon tobacco cessation quitline, while reducing television and radio advertising to promote the quitline. The "free patch initiative" added a 2-week supply of free NRT (while supplies lasted) for tobacco users registering for counselling and used an "earned" (unpaid) media promotion to generate calls to the quitline. Earned media used press releases and a news conference to gain publicity from local print, TV and radio news organisations. Promotion activities also included working with local healthcare providers, public and private insurers and public health agencies to spread the information to smokers. At the time, $20 \%$ of Oregon's adults smoked cigarettes. ${ }^{15}$ During the initiative, some insurers added NRT as a covered benefit for quitline recipients. Callers with insurance coverage were encouraged to obtain additional patches from their healthcare providers. To our knowledge, this strategy was the first to use NRT as a mechanism to promote quitline use.

This study evaluated the cost effectiveness of the free patch initiative compared to the pre-initiative programme and was the first to include quitline promotion costs as part of the analysis. We estimated the total programme and intervention costs for each programme, total cost per quit and incremental cost per additional quit and life year saved (LYS). Successful quits were defined as self reported 30-day abstinence at six months. We used data available at six months to project the incremental cost effectiveness at 12 months.

\section{METHODS}

We estimated the total programme cost and incremental cost effectiveness per quit and per LYS of the free patch initiative compared to the pre-initiative programme. Data availability limited the cost effectiveness analysis (CEA) to a programme perspective. ${ }^{16}$ We included quitline programme promotion and intervention costs, utilisation and quit rate data obtained from TPEP, F\&C, CDC and quitline callers enrolled in a six-month

Abbreviations: CEA, cost effectiveness analysis; F\&C, Free \& Clear, Inc; LYS, life year saved; NRT, nicotine replacement therapy; TPEP, Tobacco Prevention and Education Programme 
evaluation study. ${ }^{18} 18$ We compared TPEP's promotion and intervention costs before and after implementation of the free patch initiative. All costs are reported in 2004 dollars. We conducted sensitivity analyses for key programme costs and outcomes. The Western institutional review board approved the study.

\section{Quitline promotion and costs}

The quitline programme fixed costs were annual TV and radio promotion during the pre-initiative period and quitline promotion costs during the free patch initiative (when paid advertising was discontinued). TPEP used a combination of TV and radio ads that aired during day and evening hours. We estimated annual media promotion costs by averaging TV and radio ad expenditures over a 41-month period before the free patch initiative. ${ }^{19}$ Advertising production costs were obtained from CDC..$^{20}$ Costs for each ad included quarterly talent fees, tagging, duplication and other costs (mainly shipping). Talent fees are charged for a 13-week period regardless of how often the ads appeared. Most TV ads were tagged with the TPEP logo and the quitline toll-free phone number. TPEP paid talent fees, tagging and duplication costs; CDC paid shipping costs. The costs paid by CDC to produce the original ads were unavailable and are not included here. Excluding these costs probably had minimal impacts on the estimates.

The free patch initiative used no paid advertising. Instead, TPEP promoted the free NRT offer by distributing media kits to counties. The kits contained fact sheets, a cost of smoking chart, general news release, tailored news releases for minority publications, general advisories and advisories tailored to geographic areas. TPEP also sent letters, emails and broadcasts to state agencies that provide services to uninsured populations; made verbal announcements and distributed newsletters in both the public and private sectors; and distributed "free patch cards" to targeted groups and locations, including callers to the quitline.

\section{Quitline callers}

We projected annual registration calls before and after the initiative using average monthly call data for January-June 2004 and 2005. During the first three months of the initiative (October-December 2004), nearly 7000 callers registered for cessation services. All registered callers were offered free NRT, regardless of insurance status. We assumed the large announcement effect was a one-time event, so we excluded this period to estimate a more realistic call volume for future years. The overwhelming demand for services led TPEP to temporarily suspend the free NRT offer for insured callers in December 2004. Free NRT remained available to uninsured callers. Call volumes during this period fell somewhat, but remained high compared to the pre-initiative period.
Since we excluded the first three months when NRT was available for free, we expect the estimated average calls per month for January-June 2005 provide a conservative estimate of call volumes for an ongoing free NRT campaign. No other major state tobacco control initiatives occurred during the study period.

\section{Study population}

An independent survey firm recruited smokers by phone six months after they had registered for quitline services during the pre-initiative and initiative periods. All smokers $(n=1018)$ who registered for quitline service during March-May 2004 were recruited into the control group. To be eligible, smokers had to be age 18 or older, have no health related contraindications and have a valid telephone number. For the free patch initiative group, we recruited a random sample of 1574 of the 6881 smokers who registering during October-December 2004. The follow-up survey measured satisfaction with the quitline, use and costs of additional services in the last six months, smoking status and quit intentions and confidence if still smoking. The additional services measured were nonquitline individual or group counselling, medications (nicotine patch, gum, lozenge, nasal spray or bupropion) and participant paid costs.

\section{Intervention outcomes and costs}

We defined quitting as self reported 30-day abstinence at six months and conservatively assumed all eligible non-participants (excluding callers with invalid phone numbers) were treatment failures (that is, intent to treat). For all quitters, we estimated LYS using age specific remaining life expectancy, relative risk of death for current smokers and the percentage of future smoking attributable deaths that can be prevented by quitting. ${ }^{21-23}$ LYS were discounted to the present value using a real social discount rate of $3 \% .^{16}$

The cost of one 30-minute telephone counselling session was $\$ 91$. Free patch initiative recipients also received two weeks of NRT that cost $\$ 42.82$ (including shipping).

\section{Cost effectiveness analysis}

We assessed the incremental net cost of a one year free patch initiative programme (one call, NRT) to the one call (preinitiative) protocol per additional quit and per LYS. The cost estimates included annualised quitline promotion and intervention (counselling and medication) costs for each intervention strategy. We assumed the free patch initiative included two months of paid media advertising during the year. We used the following formula to estimate incremental cost effectiveness ratios:

$\left(\mathrm{TC}_{\mathrm{I}}-\mathrm{TC}_{\mathrm{PI}}\right) /\left(\mathrm{TQ}_{\mathrm{I}}-\mathrm{TQ}_{\mathrm{PI}}\right)$

where $\mathrm{TC}_{\mathrm{I}}=$ total promotion and intervention costs of the initiative, $\mathrm{TC}_{\mathrm{PI}}=$ total promotion and intervention costs of the

Table 1 Oregon tobacco quitline promotion costs before and during the "free patch initiative"

\begin{tabular}{|c|c|c|c|c|c|c|}
\hline & \multirow[b]{2}{*}{$\begin{array}{l}\text { Advertising time } \\
\text { costs (41 months) }\end{array}$} & \multicolumn{4}{|c|}{ Annual production fees } & \multirow[b]{2}{*}{ Total annual media costs" } \\
\hline & & Talent fees & Tagging & $\begin{array}{l}\text { Duplication } \\
\text { costs }\end{array}$ & Other costs & \\
\hline \multicolumn{7}{|l|}{ Pre-initiative period } \\
\hline Daytime TV ads & $\$ 503716$ & $\$ 236000$ & $\$ 570$ & $\$ 390$ & $\$ 120$ & $\$ 384509$ \\
\hline Evening TV ads & $\$ 866211$ & $\$ 176000$ & $\$ 665$ & $\$ 455$ & $\$ 140$ & $\$ 430785$ \\
\hline Radio ads & $\$ 1344964$ & $\$ 176000$ & $\$ 0$ & $\$ 455$ & $\$ 140$ & $\$ 570243$ \\
\hline Total costs & $\$ 2714890$ & $\$ 588000$ & $\$ 1235$ & $\$ 1300$ & $\$ 400$ & $\$ 1385537$ \\
\hline \multicolumn{7}{|l|}{ Free patch initiative } \\
\hline Promotion & & & & & $\$ 48600$ & $\$ 48600$ \\
\hline
\end{tabular}

*Includes annualised total media time costs over 41 months averaged $\$ 794601$.

Sources: advertising costs from TPEP staff ${ }^{19}$; production costs from CDC's Media Campaign Resource Center. ${ }^{20}$ 
Table 2 Tobacco user registration calls to the Oregon quitline before and after the free patch initiative

\begin{tabular}{|c|c|c|c|c|c|c|c|c|c|}
\hline \multirow[b]{2}{*}{ Year } & \multirow[b]{2}{*}{ Jan } & \multirow[b]{2}{*}{ Feb } & \multirow[b]{2}{*}{ Mar } & \multirow[b]{2}{*}{ Apr } & \multirow[b]{2}{*}{ May } & \multirow[b]{2}{*}{ June } & \multicolumn{2}{|c|}{6 months } & \multirow[b]{2}{*}{ Projected annual } \\
\hline & & & & & & & Total & Average & \\
\hline 2004 & 1346 & 507 & 349 & 416 & 284 & 312 & 3214 & 536 & 6428 \\
\hline 2005 & 948 & 792 & 865 & 1474 & 852 & 1892 & 6823 & 1137 & 13646 \\
\hline Difference & (398) & 285 & 516 & 1058 & 568 & 1580 & 3609 & 602 & 7218 \\
\hline
\end{tabular}

pre-initiative strategy, $\mathrm{TQ}_{\mathrm{I}}=$ total quits for the initiative and $\mathrm{TQ}_{\mathrm{PI}}=$ total quits for the pre-initiative period. We used the same formula to estimate incremental costs per LYS, substituting total discounted LYS for total quits.

\section{Sensitivity analysis}

To conduct the CEA sensitivity analysis, we estimated best and worst case scenarios for annual programme reach (registration calls), costs and quit rates. The worst case scenario assumed annual registration calls equalled the upper 95\% confidence interval (CI) of mean monthly calls and promotion spending included six months of paid advertising costs. We used the lower CI of the mean 30-day abstinence for initiative participants and the upper CI for the pre-initiative participants. The best case scenario assumed annual registration calls equalled the lower CI of mean monthly calls, promotion spending included only one month of paid advertising and $13.7 \%$ of initiative participants quit smoking. Other preinitiative measures remained the same as the reference case. Discount rates for LYS were $1 \%$ and $5 \%$ for the best case and worst case scenarios, respectively.

\section{RESULTS}

\section{Programme promotion costs}

From November 1999 to March 2002, TPEP paid about \$2.7 million (2004 dollars) for TV and radio airtime (about $\$ 800000$ annually) (table 1). Talent fees represented the primary production costs. Quarterly talent fees ranged from $\$ 1500$ to $\$ 11000$ for TV ads and $\$ 1000$ to $\$ 5000$ for radio ads. Most TV ads were tagged with the TPEP logo and the quitline toll-free phone number at $\$ 95$ for each ad. Overall, we estimated an annual cost of $\$ 1.4$ million (2004 dollars) for annual airtime and production fees for quitline promotions during the preinitiative period. To promote the free patch initiative, TPEP staff reported spending $\$ 48600$, which included $\$ 37000$ for contractor time, about $\$ 3600$ for additional staff time for programme planning and implementation and $\$ 8000$ for supplies and postage.

\section{Registration calls}

There were 3214 actual tobacco user registration calls to the Oregon quitline during January-June 2004 and 6623 calls during the same period in 2005 (table 2). Based on the monthly averages, we estimated that 6428 tobacco users registered annually for cessation services during the pre-initiative period, whereas 13646 registered annually during the free patch initiative. Excluding the impact of the initial rollout, offering free NRT more than doubled the estimated number of annual quitline users.

Registration data showed some differences between preinitiative and post-initiative callers. Compared to pre-initiative callers $(n=1018)$, registered callers during the free patch initiative $(\mathrm{n}=6881)$ were older $(44.3$ vs $40.8 ; \mathrm{p}<0.0001)$. They were less likely to be Hispanic ( $5.6 \%$ vs $8.6 \%, p<0.005)$, nonwhite ( 10.8 vs $13.2 \%, \mathrm{p}<0.05)$ and have insurance $(65.2 \%$ vs $80.2 \%, \mathrm{p}<0.0001)$ and more likely to be in the preparation stage of change for tobacco use (planning to quit in the next 30 days) $(92.7 \%$ vs $82.1 \%, p<0.0001) .{ }^{24}$

\section{Study participant characteristics}

Among 1018 registered smokers in the pre-initiative period, 661 had valid contact information. Of those contacted, 320 (48.4\%) were eligible, agreed to participate and completed the six month follow-up survey. In the free patch initiative sample ( 1574 callers), 1208 had valid phone numbers and 639 (52.9\%) agreed to participate. Responders did not significantly differ from non-responders in age, sex, years of smoking or cigarettes per day for both the pre-initiative and initiative callers.

Among those who completed the survey, the free patch initiative callers were older and less motivated to quit at baseline compared to pre-initiative participants (table 3). Respondents did not significantly differ by sex, education, employment, race-ethnicity or amount smoked at registration. At follow-up, initiative respondents were more likely to report having quit smoking compared to pre-initiative participants. Assuming non-responders were smokers, 30-day abstinence was significantly higher for initiative registrants (15.7\%; CI $13.7 \%$ to $17.8 .9 \%)$ compared to pre-initiative registrants $(8.2 \%$; CI $6.1 \%$ to $10.3 \%)$.

\section{Cost effectiveness of the "free patch initiative"}

We present estimated annual quitline use, costs and cost effectiveness in table 4 for the reference, best case and worst case scenarios. For the reference case, we estimated that each year 2142 of the 13646 registered callers would quit smoking cigarettes if offered a free two-week supply of NRT, based on 30-day abstinence rates. With no NRT offer, 527 of 6428 callers would quit each year. The estimated total annual cost of the free patch programme was about $30 \%$ more than the cost of the pre-initiative programme. However, total cost per quit was \$2688 lower for free NRT recipients $(\$ 1050)$ compared to preinitiative callers $(\$ 3738)$. The free patch initiative programme cost $\$ 174$ more per additional quit and $\$ 86$ more per additional LYS.

Varying the model assumptions or adding the cost of additional services used by participants had little impact on the results. For the best case scenario, annual call volume and quits increased compared to the reference case free patch programme, while total costs declined. Incremental cost per quit and LYS relative to the pre-initiative programme fell to $\$ 70$ and $\$ 22$, respectively. For the worst case scenario, the incremental cost effectiveness per quit and per LYS increased to $\$ 525$ and $\$ 353$ for initiative callers compared to pre-initiative callers. However, total cost per quit remained lower for initiative participants $(\$ 1413)$ than for pre-initiative callers (\$2976).

\section{DISCUSSION}

The free patch initiative was a highly cost effective programme for increasing the reach and effectiveness of the Oregon quitline. Compared to paid media promotion for a single telephone counselling session, shifting media promotion resources to fund a free NRT offer doubled the number of 
Table 3 Characteristics of survey respondents before and after the "free patch initiative"

\begin{tabular}{|c|c|c|c|}
\hline Characteristics & $\begin{array}{l}\text { Pre-initiative period } \\
(\mathrm{n}=320)\end{array}$ & $\begin{array}{l}\text { Free patch initiative } \\
(n=639)\end{array}$ & p Value \\
\hline \multicolumn{4}{|l|}{ At registration } \\
\hline Mean age & 40.9 & 49.1 & $<0.0001^{*}$ \\
\hline Female & $69.1 \%$ & $67.8 \%$ & NS \\
\hline High school or less & $53.8 \%$ & $49.9 \%$ & NS \\
\hline Hispanic & $4.4 \%$ & $3.8 \%$ & NS \\
\hline Non-white & $17.8 \%$ & $10.2 \%$ & NS \\
\hline Heavy smoker ( $\geqslant 1$ pack/day) $†$ & $45.9 \%$ & $51.0 \%$ & NS \\
\hline Mean motivation to quit (SD) & $8.0(1.9)$ & $6.6(3.8)$ & $<0.0001^{*}$ \\
\hline \multicolumn{4}{|l|}{ At follow-up } \\
\hline 7-day abstinence & $19.0 \%$ & $33.6 \%$ & $<0.05$ \\
\hline 30-day abstinence & $16.4 \%$ & $29.7 \%$ & $<0.001$ \\
\hline Intent to treat abstinence & $8.2 \%$ & $15.7 \%$ & $<0.001$ \\
\hline Purchased additional services & $30.5 \%$ & $49.8 \%$ & $<0.0001$ \\
\hline If purchased, mean costs & $\$ 39.50$ & $\$ 55.01$ & $<0.001^{*}$ \\
\hline
\end{tabular}

registered callers. The number of quitters increased fourfold and the cost per quit fell more than $\$ 2688$.

The annual free patch initiative reached an estimated $2.6 \%$ of Oregon's 532000 smokers, excluding the initial roll-out period, while $1.2 \%$ of smokers registered for service during the preinitiative period. These results correspond to reach estimates of $0.5 \%-5 \%$ achieved by other state quitlines offering free NRT while maintaining their paid media campaigns. ${ }^{9-12}$ Over $3 \%$ of Maine smokers call the quitline annually using clinic outreach to promote the free NRT offer..$^{10}$ In 2003, the New York State quitline offered 2-6 weeks of free NRT to callers from selected areas of the state and used earned media publicity to promote the programme. Call volumes increased in all areas and overwhelmed limited NRT supplies, thus limiting reach to $<1 \%$ in most of the state. ${ }^{12}$ About $5 \%$ of New York City smokers called the quitline over a six week period. ${ }^{9}$ The Minnesota quitline added free NRT to its multisession counselling protocol in 2002 with its existing paid media. ${ }^{11}$ Call volumes increased fourfold.

Table 4 Use and cost effectiveness of the free patch initiative compared to the pre-initiative programme

\begin{tabular}{|c|c|c|}
\hline Outcome measure & Pre-initiative programme & Free patch initiative \\
\hline \multicolumn{3}{|l|}{ Reference case } \\
\hline Registered tobacco users & 6428 & 13646 \\
\hline Quit rate* & $8.2 \%$ & $15.7 \%$ \\
\hline Quitters & 527 & 2142 \\
\hline Life years saved (3\% DR) & 1246 & 4502 \\
\hline Total programme costs & $\$ 1970085$ & $\$ 2250484$ \\
\hline Promotion costs & $\$ 1385137$ & $\$ 424376$ \\
\hline Intervention costs & 584948 & $\$ 1826108$ \\
\hline Cost/quit & $\$ 3738$ & $\$ 1050$ \\
\hline \multicolumn{3}{|l|}{ Incremental cost effectiveness $\dagger$} \\
\hline Per quit & NA & $\$ 174$ \\
\hline Per life year saved (3\% DR) & NA & $\$ 86$ \\
\hline \multicolumn{3}{|l|}{ Best case scenario } \\
\hline Registered tobacco users & 6428 & 13957 \\
\hline Quit rate* & $8.2 \%$ & $17.8 \%$ \\
\hline Quitters & 527 & 2484 \\
\hline Life years saved (1\% DR) & 1895 & 7493 \\
\hline Total programme costs & Same as reference case & $\$ 2107827$ \\
\hline Promotion costs & " & $\$ 240111$ \\
\hline Intervention costs & " & $\$ 1867716$ \\
\hline Cost/quit & " & $\$ 848$ \\
\hline \multicolumn{3}{|l|}{ Incremental cost effectiveness $†$} \\
\hline Per quit & NA & $\$ 70$ \\
\hline Per life year saved ( $1 \%$ DR) & NA & $\$ 22$ \\
\hline \multicolumn{3}{|l|}{ Worst case scenario } \\
\hline Registered tobacco users & 6428 & 13335 \\
\hline Quit rate* & $10.3 \%$ & $13.7 \%$ \\
\hline Quitters & 662 & 1827 \\
\hline Life years saved (5\% DR) & 1079 & 2812 \\
\hline Total programme costs & Same as reference case & $\$ 2582116$ \\
\hline Promotion costs & " & $\$ 797617$ \\
\hline Intervention costs & " & $\$ 1784499$ \\
\hline Cost/quit & $\$ 2976$ & $\$ 1413$ \\
\hline \multicolumn{3}{|l|}{ Incremental cost effectiveness $\dagger$} \\
\hline Per quit & NA & $\$ 525$ \\
\hline Per life year saved (5\% DR) & NA & $\$ 353$ \\
\hline
\end{tabular}


Providing two weeks of free NRT for Oregon quitline callers nearly doubled intent to treat quit rates at six months compared to no NRT. Other quitline studies report similar benefits. Thirty-day abstinence was $22.5 \%$ for Maine smokers who received six weeks of NRT and multisession counselling compared to $12.3 \%$ of callers with counselling only. ${ }^{10}$ Twenty per cent of NYC callers receiving NRT and a single follow-up call were not smoking after six months. ${ }^{9}$ In Minnesota, quit rates increased from $10 \%$ to about $18 \%$ with free NRT. ${ }^{11}$

Cost and cost effectiveness data for the free patch initiative were similar to economic evaluations of free NRT offers. Maine's intervention cost $\$ 1344$ per quit. ${ }^{10}$ In Minnesota, costs per quit were $\$ 1362$ for the no NRT programme and \$1934 for the free NRT programme. ${ }^{11}$ Intervention cost per quit for New York's free NRT offer was under $\$ 500 .{ }^{9}{ }^{12}$ However, our study was the first to include quitline promotion costs as part of the analysis. We estimated that annual paid media costs were \$215 per registered tobacco user for the pre-initiative programme and less than $\$ 4$ per caller during the free patch initiative.

By substituting free NRT for paid media expenditures, TPEP was able to dramatically reduce the average cost per quit. However, the free NRT prompted more calls and increased the total annual cost of the programme somewhat. The result was a small but positive incremental cost per quit compared to the pre-initiative programme. This study showed using scarce programme resources to fund free NRT instead of paid media promotion was a good value even for the worst case scenario. Costs/LYS were less than the \$1000-\$5000 per LYS typical for other tobacco interventions and substantially below other commonly available preventive services (for example, mammography). ${ }^{25} 26$

This study has several limitations. The short follow-up period did not allow us to assess longer term quit rates and costs. The relatively low response rate to the six-month survey may also have influenced the accuracy of the quit rates, since all nonresponders were assumed to be treatment failures. A higher response rate would have likely improved cost effectiveness, since some of those not reached may have quit. We excluded the initial period of the campaign when the bulk of the free NRT was actually distributed, assuming that this level of call volume would not be sustained in an ongoing free patch programme. However, this likely underestimated the effect free NRT could provide. We did not biochemically confirm smoking status at follow-up. However, evidence suggests false reporting is minimal for low intensity interventions with no face to face contact. ${ }^{27}$ We assumed a sustainable quitline promotion programme would require periodic paid media advertising. We do not know how calling rates may vary over time. We also do not know the effectiveness of a month long media campaign conducted once or twice a year. However, we expect declining marginal benefits in terms of call volume from increased media spending. We are sceptical that a paid media campaign can match the call volumes achieved by the free patch initiative.

We were unable to capture any quits that may have been caused solely by viewing the media campaigns. Zhu and others have proposed that an important benefit of quitlines is their enhancement of quit attempts in the larger population regardless of whether people actually call for help. ${ }^{29}$ However, this effect has only been measured in one instance ${ }^{30}$ and it is not clear how large an effect, if any, is produced. In addition, it is unclear whether this collateral benefit is best achieved via mass media, healthcare provider promotion, word of mouth, or all three. The availability of free patches and the much cheaper healthcare provider promotion may increase healthcare provider and word of mouth cessation activity more than mass media.

Though not part of this analysis, initiative participants reported spending more for additional cessation products

\section{What this paper adds}

- Some state funded telephone tobacco quitlines offer free NRT to tobacco users registering for service. In these instances, free NRT has been added to the existing quitline promotion activities that include paid TV and radio advertising. In 2004, Oregon became the first state to promote quitline services with a strategy that combined a free NRT offer and earned (unpaid) media.

- This study demonstrates that shiffing expenditures from media promotion to an NRT offer is a highly cost effective tobacco control strategy for state programmes.

(\$27.39, range \$23.50-\$31.30), primarily for additional patches and bupropion, than pre-initiative callers $(\$ 12.04$, range $\$ 8.35-$ $\$ 15.73)$. Only 10 study participants $(<0.5 \%)$ reported obtaining additional NRT that was partially covered by health insurance, even though the free patch initiative aimed to increase use of covered cessation services.

The CEA results were influenced by the large increase in number of calls generated by the earned media promotion strategy compared to paid media. That difference raises the possibility of TPEP using paid media to increase the number of annual calls to the same level achieved by the earned media and free NRT offer. We looked at how much this strategy would cost, its effect on quitting and how these results compared to the earned media approach of the free patch initiative. We answered these questions by multiplying the average paid media cost per call and quit rate for the pre-initiative programme by 13646 callers. Assuming paid TV/radio ads had a constant effect on quitline calls (that is, \$215 per registration call) TPEP would spend $\$ 4.2$ million on paid advertising and cessation counselling for 13646 callers. Of these callers, we estimated that 1119 would quit. Thus, we estimated that the free patch initiative (even with two months of paid media) could save TPEP nearly \$2 million and help 1023 more people quit than if they had increased call volumes using only paid media.

As in other states, extensive earned media coverage of the quitline's free patch offer generated a large initial call volume during the initial roll-out of the initiative. We expect this was a one-time phenomenon. In the future, media outlets can include the availability of free quitline services as part of news reports about tobacco control policies, the impacts of tobacco use and benefits of quitting. We expect future call volumes will depend largely on TPEP's continued efforts to promote the quitline among healthcare providers, insurers and public health agencies.

Overall, the free patch initiative appears to have been a very effective and cost effective programme that dramatically increased the number of quitters among Oregon quitline callers. This study shows that expanding cessation services to include medications can substantially increase the reach and effectiveness of state funded quitline services. Given persistent resource limitations, state tobacco control programme managers should consider reallocating portions of their media promotion budget to cover medications.

\section{ACKNOWLEDGEMENTS}

We thank Mona Deprey from Free and Clear, Inc, for coordinating study activities and Cathryn Cushing and Nancy Clarke from the Oregon Department of Human Services for their support throughout the study. We'd also like to thank Jennifer Coury for her editorial review and assistance and the telephone counsellors who served and continue to serve Oregon quitline callers. 


\section{Authors' affiliations}

Jeffrey L Fellows, Terry Bush, Tim McAfee, John Dickerson, Center for Health Research, Kaiser Permanente Northwest, Portland, Oregon, Free \& Clear, Inc, Seattle, WA, USA

Supported by: Oregon Tobacco Prevention and Evaluation Program and the Centers for Disease Control and Prevention.

Competing interests: JLF and JD have no competing interests. TB and TMCA are with Free \& Clear, Inc, which is a for-profit company providing telephone counselling services.

\section{REFERENCES}

1 Centers for Disease Control and Prevention. Annual smoking-attributable mortality, years of potential life lost, and economic costs - United States, 19951999. Morb Mortal Wkly Rep 2002;51:300-3.

2 Fiore MC, Bailey WC, Cohen SJ, et al. Clinical practice guideline: treating tobacco use and dependence. Rockville, MD: Public Health Service, 2000.

3 Hopkins DP, Briss PA, Ricard CJ, et al. Reviews of evidence regarding interventions to reduce tobacco use and exposure to environmental tobacco smoke. Am J Prev Med, 2001;20(2 Suppl), 16-66.

4 Ossip-Klein DJ, Mclntosh S. Quitlines in North America: evidence base and applications. Am J Med Sci 2003;326:201-5.

5 Stead LF, Perera R, Lancaster T. A systematic review of interventions for smokers who contact quitlines. Tob Control 2007;16(Suppl I):i3-8.

6 Centers for Disease Control and Prevention. Telephone quitlines: a resource for development, implementation, and evaluation, Final ed. Atlanta, GA: US Department of Health and Human Services, Centers for Disease Control and Prevention, National Center for Chronic Disease Prevention and Health Promotion, Office on Smoking and Health, 2004.

7 Fiore MC, Croyle RT, Curry SJ, et al. Preventing 3 million premature deaths and helping 5 million smokers quit: A national action plan for tobacco cessation. Am J Public Health 2004;94:205-10.

8 North American Quitline Consortium. Quitlines of North America and Europe 2006, [updated 2007]. Phoenix, AZ: North American Quitline Consortium, Available at http://www.naquitline.org. Accessed 21 May, 2007

9 Miller N, Frieden TR, Liu SY, et al. Effectiveness of a large-scale distribution programme of free nicotine patches: a prospective evaluation. Lancet 2005;365: 1849-54.

10 Swartz SH, Cowan TM, Klayman JE, et al. Use and effectiveness of tobacco telephone counseling and nicotine therapy in Maine. Am J Prev Med 2005;29:288-94

11 An LC, Schillo BA, Kavanaugh AM, et al. Increasing reach and effectiveness of a statewide tobacco quitline after addition of access to free nicotine replacement therapy. Tob Control 2006;15:286-93.

12 Cummings KM, Fix B, Celestino P, et al. Reach, efficacy, and cost-effectiveness of free nicotine mediation giveaway programs. J Public Health Management Practice 2006; 12:37-43.

13 Oregon Department of Human Services. 2003-2005 Tobacco prevention \& education program report, Tobacco Prevention and Education Program. Oregon Department of Human Services, 2005. Available at: http://www.oregon.gov/ DHS/ph/tobacco/ar03-05.shtml. Accessed 30 May, 2007.
14 Centers for Disease Control and Prevention. Best practices for comprehensive tobacco control programs - August 1999. Atlanta GA: US Department of Health and Human Services, Centers for Disease Control and Prevention, National Center for Chronic Disease Prevention and Health Promotion, Office on Smoking and Health, August, 1999.

15 Centers for Disease Control and Prevention. State-specific prevalences of cigarette smoking and quitting among adults-United States, 2004. Morb Mortal Wkly Rep 2005;54:1 124-7.

16 Haddix A, Teutsch SM, Corso PS. Prevention effectiveness: a guide to decision analysis and economic evaluation, 2nd ed. New York: Oxford University Press, 2003.

17 Free and Clear, Inc. Oregon Tobacco Quitline-the Oregon "free patch initiative": six-month report on the insured, 2005. Seattle, WA: Free and Clear, Inc, 2005

18 Free and Clear, Inc. Oregon tobacco quitline: results of the free patch initiative among the uninsured. A randomized control trial \& cost effectiveness analysis, 2006. Seattle, WA: Free and Clear, Inc, 2006.

19 Mosbaek C, Austin DF, Stark MJ, et al. The association between advertising and calls to a tobacco quitline. (unpublished)

20 Centers for Disease Control and Prevention. Media Campaign Resource Center, Office on Smoking and Health, Available at http:/www.cdc.gov/tobacco/mcrc, Accessed on 14 December 2005.

21 Arias E. United States life tables, 2003. National vital statistics reports; vol 54 no 14 Hyattsville, MD: National Center for Health Statistics, 2006. Available at http:// www.cdc.gov/nchs/data/nvsr/nvsr54/nvsr54_14.pdfAccessed 10 May, 2007

22 Thun MJ, Day-Lally C, Myers DG, et al. Trends in tobacco smoking and mortality from cigarette use in Cancer Prevention Studies I (1959 through 1965) and II (1982 through 1988). In: Changes in cigarette-related disease risks and their implication for prevention and control. Smoking and tobacco control monograph 8. Bethesda, Maryland: US Department of Health and Human Services, Public Health Service, National Institutes of Health, Nation Cancer Institute, 1997:305382, NIH publication no 97-4213.

23 US Department of Health and Human Services. The health consequences of smoking: A report of the surgeon general, US Department of Health and Human Services, Centers for Disease Control and Prevention, National Center for Chronic Disease Prevention and Health Promotion, Office on Smoking and Health, 2004.

24 Prochaska, James O, DiClemente, Carlo C. Stages and processes of self-change of smoking: toward an integrative model of change. J Consult Clin Psychol 1983;51:390-5.

25 Cromwell J, Bartosch WJ, Fiore MC, et al. Cost-effectiveness of the clinical practice recommendations in the AHCPR guideline for smoking cessation. Agency for Health Care Policy and Research. JAMA 1997;278:1759-66.

26 Warner KE. Cost effectiveness of smoking-cessation therapies. Interpretation of the evidence-and implications for coverage. Pharmacoeconomics 1997; 11:538-49

27 Patrick DL, Cheadle A, Thompson DC, et al. The validity of self-reported smoking: A review and meta-analysis. Am J Public Health 1994;84:1086-93.

28 SRNT Subcommittee on Biochemical Verification. Biochemical verification of tobacco use and cessation. Nicotine Tob Res 2002;12:235-43.

29 Zhu S-H. Increasing Cessation in the population: quit attempts vs. uccessful quit attempts, Oral presentation for the World Conference on Tobacco or Health, Washington DC, July, 2006.

30 Ossip-Klein DJ, et al. Effects of a smoker's hotline: results of a 10-county self-help trial. J Consult Clin Psychol 1991;59:325-32. 